\title{
JOSÉ DE LA PEÑA Y ¿TORO? APUNTE BIOGRÁFICO PARA UN ARTISTA PROMETEDOR*
}

Recientemente se ha dado a conocer su lugar de nacimiento y, en efecto, nació en La Seca, lugar correspondiente al partido judicial de Medina del Campo y dependiente de su abadía ${ }^{1}$. Pero no en 1614, como se dice que dijo José de la Peña, tal cual, maestro de obras del monasterio de San Martín Pinario, luego de la catedral y mucho antes, correcto retablista, ensamblador y entallador de lo que le saliese al paso por tierra de Campos. El artista, con todas las letras, como se sabe y se repite, había llegado a Santiago en 1652 procedente de Salamanca para trabajar en el convento de los benitos. La noticia asentó, con arriesgada certitud, un gentilicio y una formación que no le corresponden y que tampoco sirven para explicar ciertos modismos o, en definitiva, para recrear un estilo que es fruto de un viaje más accidentado, lleno de matices, algunos felices, otros no tan gratos ${ }^{2}$.

Con una "capa arenosa que tenia puesta" y los grilletes, que lo maniataban para vergüenza pública, un tal "Jossep de la Peña ensanblador, veçino de la Seca del Rey" se resignaba ante la vigilancia de Antonio de Simancas, alguacil mayor de la villa, más presto a satisfacer los intereses de la familia Carassa que a impartir justicia en una cuestión abierta, como siempre, a la ambigüedad más fastidiosa. La villa no era La Seca, sino Torrelobatón. En 1631, la pequeña capilla de don Baltasar de Medina Carassa y su mujer, en la iglesia de Santa María, estaba casi dispuesta, con su deliciosa cúpula encalada, el disfraz de la policromía y la leyenda de su patronato. El retablo no podía faltar y se remató, por voluntariosa postura, en un joven tracista que se comprometió a levantarlo asumiendo, además, la talla de la figura de su advocación, San José, y del relieve escultórico del ático, dedicado -en principio- a la historia de Santa Mónica. Como en el precio aireado se incluían, aparte de la propia arquitectura y la figuración, el dorado y pintura

\footnotetext{
* El presente estudio es un avance de algunos datos reunidos en mi tesis doctoral, Vega y Verdugo, Peña de Toro y la introducción del Barroco en Compostela, que será defendida en breve.

${ }^{1}$ Cfr. Fernández Gasalla, L., "El arquitecto José de la Peña de Toro (1614-1676)”, Compostellanum, volumen LI, números 3-4, 2007, p. 325

2 Para lo que aquí concierne, véanse, Bonet Correa, A., La arquitectura en Galicia durante el siglo XVII, Madrid, 1984, pp. 292-309; Chamoso Lamas, M., "La fachada del Obradoiro de la Catedral de Santiago", Archivo Español del Arte y Arqueología, t. XII, 1936, pp. 223-224; Ídem, "El Pórtico Real de la Quintana de la catedral de Santiago", Cuadernos de Estudios Gallegos, t. I, 1944, pp. 45-53; López Ferreiro, A., Historia de la Santa A.M. Iglesia de Santiago, t. IX, Santiago, 1907, p. 294; Pérez Costanti, P., Diccionario de artistas que florecieron en Galicia durante los siglos XVI y XVII, Santiago, 1930, pp. 423-425; Rodríguez G. de Ceballos, A., "Juan Moreno y la arquitectura del protobarroco en Salamanca", Archivo Español del Arte y Arqueología, 1976, pp. 247-271; "Intercambios artísticos entre Galicia y Salamanca", VI Congreso Español de Historia del Arte. Los caminos y el arte. II, Santiago, 1989, pp. 247-360; Ídem, Estudios del Barroco Salmantino. El Colegio Real de la Compañía de Jesús (1617-1779), Salamanca, 1985, p. 56
} 
del mueble y como el adjudicatario de la obra no cumplió con esta última condición, se acudió a la justicia y ésta, a un ensamblador que pecaba de bisoñez a la hora de negociar el que acaso sería su primer encargo a título individual. El asunto fue especialmente engorroso para el reo que, pese a todo, no dudó en darse a la fuga, comprometiendo a su vigilante y, para alivio de éste, a los fiadores que habían intercedido en la escritura de contrato a favor del demandado, quienes, finalmente, pagaron el desaguisado ${ }^{3}$.

Todo este lío forma parte del inicio renqueante y alambicado, del que años después, por prestigio onomástico, firmaría como hoy se conoce a José de la Peña y Toro, maestro de cantería, arquitecto al servicio del canónigo-fabriquero don José de la Vega y Verdugo, autor del cimborrio cupulado de la basílica, del Pórtico Real, del cierre de la Quintana, y también, claro, de la Torre de las Campanas, entre otras cosas que aquí no vienen al caso. Pero esto sucedió tantos años después, que los porqués y el cómo, esbozados por inercia para explicar esa obra de cantería, se desdibujan hasta diluirse en la simple conjetura por la falta de datos. Es necesario despejar ese mar de dudas para calibrar con certeza un primer barroco gallego tímido pero prometedor. Este estilo, al que llegó por intuición y mucho trabajo previo, nació, como digo, antes de lo estipulado, en un villorrio cuya conexión con Santiago se cifraba a través de las rentas del Voto. Cuando llegó a Compostela, no era joven; tenía detrás un largo camino recorrido y había vivido más de lo que luego viviría. Desde luego, era ya un artista maduro, plenamente formado, aunque sólo fuera en el ámbito de la escultura, talla y ensamblaje de retablos y sillerías de coro.

En enero de 1671, apurando sus últimos años como director de las obras catedralicias, el viejo Peña actúa como testigo pericial en el pleito sobre la capilla que había fundado Andrés Núñez Buceta en la iglesia parroquial de Vilagarcía de Arousa. Como requería la idiosincrasia del testimonio, el artista delata, al pie de su dictamen, ser "de hedad de çinquenta y siete años poco mas o menos", lo que retardaría la fecha de su nacimiento hasta el año $1614^{4}$. Afirmaciones como éstas deben tomarse siempre con mucha cautela pues la edad que se suele proponer al pie de ese tipo de relatos periciales es aproximativa, muy dudosa: los "poco mas o menos" que siguen a este tipo de puntualizaciones, no son arbitrarios.

Después, en septiembre de 1672, y también como testigo, acompaña a Domingo Bugallo Salmonte, justicia y alcalde ordinario de Santiago, para exponer su opinión acerca de la "tan considerable falta de agua en las fuentes de dicha ciudad, tan de perjuiçio de sus vecinos". Tras un concienzudo informe, firma su declaración asegurando contar con "cinquenta y seis años poco mas o menos" lo que sugiere la fecha de 1615 ó $1616^{5}$.

El problema se repite en 1675, meses antes de morir. La dichosa arqueta de San Miguel, que lo abastecía todo, vuelve a provocar tiranteces en la ciudad. Se recurre al maestro para ilustrar la querella que presentan el Cabildo y la comunidad de San Martín contra la condesa de Priegue, por

\footnotetext{
${ }^{3}$ Habían firmado el contrato el 28 de febrero de 1631. Archivo Histórico Provincial de Valladolid (en adelante A.H.P.V.), leg. 5006, fols. 44r-47v. y 166r-167v. Puede verse un extracto de las condiciones del contrato al final de este trabajo. De todos modos, el texto ya era conocido y está publicado desde hace tiempo, pero sin haberse identificado el ensamblador de La Seca con el arquitecto que salió de Salamanca. Véase Parrado del Olmo, J.M., Catálogo Monumental de la Provincia de Valladolid. Antiguo Partido Judicial de Mota del Marqués, Valladolid, 1976, pp. 223-224 y documentos 2, 3, 4 y 5 .

${ }^{4}$ Archivo del Reino de Galicia, leg. 1886, n58, fol. 566v. Este creo que ha sido el documento esgrimido últimamente para acuñar el año de nacimiento del maestro, (cfr. Fernández Gasalla, L., art. cit., p. 325) El pleito lo han estudiado Goy Diz, A. y Folgar de la Calle, Ma . del Carmen, "Melchor de Velasco y la Iglesia Parroquial de Vilagarcía de Arousa. Nuevos datos sobre la capilla del Rosario", Quintana, n 2, 2003, pp. 227-250

5 Archivo de la Catedral de Santiago, (en adelante A.C.S.) leg. IG265, Repartos de arbitrios para obras de fuentes y cañerías, calles, murallas, caminos y cuarteles y para gastos de pestes, s.f. No tiene desperdicio el memorial de reparos y sutiles observaciones ofrecido por José de la Peña, tan meticuloso en el detalle de cada reparación como en el presupuesto.
} 
cuya huerta pasaba un conducto clave en la distribución del agua. Su exposición, por fin bajo el epíteto de "maestro de arquitectura", es otra demostración de profesionalidad que aquí no interesa. Sí, que reside en la ciudad "desde beinte y quatro años a esta parte" y que es "de hedad de sesenta años, poco mas o menos", de lo que se deduce la misma de $1615^{6}$.

A veces la cronología encorseta los hechos y los predispone a ciertas conclusiones que pecan de cierto determinismo, avocando el análisis de tal o cual asunto al vicio de la etiqueta en función del año dado. Pero otras veces es tan útil, que vale la pena cerciorarse si ese año es o no determinante.

Siendo un completo desconocido, y en La Seca, afirmó ser mayor de edad cuando sólo rozaba esa mayoría. La ocasión y la mentira creo que merecieron la pena. El pueblecito estaba sujeto, en 1628, a los desmanes de sus regidores, que actuaban con total impunidad para desesperación de sus vecinos: "Deçimos que en este dicho lugar ay tres ofiçios rexidores que al pressente usan y exerçen Martin Rodriguez Moyano y Pedro Ruiz de Rio Mayor y Alonso Rodriguez, con titulos de Su Magestad y perpetuydad de cuyos exerciçios se a bisto por expiriencia que an resultado y resultan al consexo deste lugar y veçinos del, grandisimos danos ansi por el mal gobierno como que [...] atropellan a los pobres y a otros vecinos deste lugar como personas que estan aseñoreados del, que todas estas caussas y otras muchas que ay lexitimas an mobido nuestros animos para reparar tantos daños como an resultado y resultan por ser los dichos reximientos perpetuos"7.

Dado el nivel de analfabetismo que lastraba a la población, fue necesaria la firma de todo vecino que la supiese dibujar para reunir el elenco de autógrafos deseado para efecto de que "dichos ofiçios de Reximientos perpetuos se conssuman en este concexo y que sean anales". Por eso Joseph de la Peña, a secas, no dudó en hacerlo, estampando su nombre y acompañándolo por la marca que lo identificaría a lo largo de los documentos notariales que refrendarían su periplo artístico ${ }^{8}$. Según esta primera noticia, habría nacido en los primeros años del siglo XVII.

La verdad es que lo hizo, seguramente, en 1608 ó 1609. La partida bautismal no ofrece dudas sobre la identidad del niño debilucho que atropelladamente se llevó a la iglesia de Santa María para asistir a su bautismo de acuerdo con los cánones, pues ya lo había recibido extra ecclesiam, por razones de enfermedad, en la casa que poseía su familia. José de la Peña, hijo de Pedro de la Peña e Isabel de Cepejón -y no Isabel de Toro, como luego se verá- recibió los santos óleos el 12 de enero de $1609^{9}$.

El error del apellido Toro asociado al de su madre procede de otro pequeño embuste que también se le puede perdonar al maestro. En 1671, José Manuel de la Peña, su único hijo varón, ante la necesidad de un expediente de limpieza que probase, precisamente, la ausencia de ascendentes judíos y moros, solicita a Salamanca, a instancias del artista, la partida de su bautizo ${ }^{10}$. El futuro

6 A.C.S. Idem., s.f. El notario que de ello dio fe era Alberto Collazo de Soto.

7 A.H.P.V., leg. 6480, fol. 146r. Ante el notario Rodrigo Cepejón.

8 Ibídem. Meses después, La Seca adquiere el rango de Villa, y se nombran como alcaldes ordinarios a Cristóbal de Ayllón y Pedro Labajo. Sobre su historia, véase A. Suárez Aláez, Historia de la Villa de la Seca, Valladolid, 1997.

9 Archivo General Diocesano de Valladolid (en adelante A.G.D.V.), Libro $5^{\circ}$ de Bautizados de La Seca, 1594-1598, fol. 183v: "Yo, el doctor Rodrigo Moyanos, clerigo, cura desta yglesia del lugar de la Seca, ynpuse los santos oleos segun horden y forma de la Santa Yglesia Romana a Josepe, hijo legitimo de Pedro de la Peña y de su mujer, Isabel Cepejona. Estaba babtiçado extra eclesiam por nezesidad, para el alivio de su enfermedad, y le baptizo el bachiller Juan Nabarro, clerigo beneficiado en la dicha yglesia y fue su padrino Nicolas de Frutos y madrina Paula Gutierrez, mujer de Diego Cepejon, todos vecinos del dicho lugar y la firme en doçe dias del mes de enero año de mil y seysçientos y nueve años".

10 "En diez y siete dias del mes de otubre deste año de mill y seiscientos y quarenta y ocho años, yo, Santiago Ximenez, cura de la yglesia de Señor San Voal desta ziudad, baptize a Jusepe, hijo de Joseph de la Peña y Doña Ysabel de Lillo, fueron sus padrinos el lizenciado Domingo Rodriguez, clerigo presbytero, su madrina, Doña Sabina de Mendoza. Fueron testigos, Julian de la Peña Toledo y Francisco Martin, sacristan de la dicha yglesia y les adverti el parentesco espiritual". Archivo Histórico Universitario de Santiago (en adelante, A.H.U.S.), protocolo 1472, (al que también hace referencia Fernández Gasalla, L., art. cit., p. 327) fol. 169r. 
clérigo había sido bautizado, es cierto, en la parroquia salmantina de San Boal. Hasta aquí no hay sorpresa alguna. Pero cuando se recibe copia de la partida y el todavía estudiante se refiere a sus ancestros -a los que nunca conoció- es cuando se adivina el gazapo, calzado, imagino, por el propio Peña de Toro: "mis abuelos paternos han sido Pedro de la Peña y Ysavel de Toro, vezinos de la villa de la Seca, de la abbadia de Medina del Canpo y los maternos fueron Alonsso Perez de Noja y doña Ysavel de Lillo, vezinos que fueron de la çiudad de Valladolid, y todos ellos y sus mayores linpios de linpia sangre, cristianos viexos deszendientes de tales, libres de toda mala rassa de judios, moros conberssos y san benitados"11.

Ni Pedro de la Peña era cantero, ni provenía de Cantabria, como se ha sugerido, pero, sin duda, fue quien enseñó el oficio, y creo que bastante bien, a su hijo, al que puso el nombre del abuelo, vecino que había sido de Paredes de Nava. Su boda con la citada Isabel de Cepejón, cuya madre se llamaba Ana de Toro, aclara la procedencia palentina del progenitor, y explica el segundo apellido de la familia materna ${ }^{12}$.

Pedro de la Peña se instruyó como ensamblador, posiblemente, en el ambiente próspero de la escultura y arquitectura de los retablos que se producían en Palencia acariciando ya el siglo $\mathrm{XVII}^{13}$. De él, curiosamente, se tienen noticias relacionadas con sus intervenciones por tierras de Medina del Campo aunque, obviamente, nunca se vio el nexo paterno filial que le unía a nuestro artista. En 1607, por ejemplo, se le pagaron 11.220 maravedís por la reja de la capilla bautismal de la iglesia de San Boal, pero no la de Salamanca, sino la de Pozaldez ${ }^{14}$. Es, exactamente, el Pedro de la Peña, "ensamblador vezino de la Seca" citado en el libro de fábrica del mismo templo en relación al cobro de 4692 maravedís por el retablo que se proponía hacer, dedicado a Nuestra Señora, a petición de un tío suyo, el clérigo Pedro Corroto. No se conservan ni éste ni el de San Miguel, contratado en 1613 por idéntico cliente. Tampoco la sillería de coro que debió de labrar, hacia 1612, para la parroquial de Santa María de la villa aludida ${ }^{15}$.

Sin embargo, para hacernos una idea de su estilo, me parece que podría ser suyo el retablo del Cristo de Corroto, fechado a finales del XVI y que se conserva en la recurrida iglesia de San Boal. En el lienzo que ocupa la única calle de la máquina, se pintó en posición orante al patrono, el presbítero Pedro Corroto. Es probable, por qué no, que asignase el ensamblaje a su sobrino ${ }^{16}$.

11 Ídem, fol. 170r.

12 "En diez dias del mes de julio del año de mil y seiscientos y seis anos, yo, Alonso de Toro, clerigo benefiçiado en la yglesia de Santa Maria del lugar de la Seca y coadjutor del cura della, certifico que, habiendo precedido las tres canonicas municiones que manda el Concilio de Trento, en tres dias festivos continuos y no se habiendo opuesto impedimento o caso canonico, por donde el Sacramento del Matrimonio se pudiere impedir con licencia del señor Vicario de la Villa de Medina del Campo, hechas las dichas muniçiones entre Pedro de la Peña, hijo de Joseph de la Peña y de Bernardina Rodriguez, vecinos de la villa de Paredes de Nava, i Ysavel Cepejon, hija de Nicolas Zepejon y de Ana de Toro, vecinos desse dicho lugar, con la dicha licencia del dicho señor Vicario en mi presencia contraxeron el dicho matrimonio por palabras de pressente y luego les administre las bendiciones nupciales y dixe la misa..."A.G.D.V., Libro $2^{\circ}$ de desposados y velados. Año 1606, fol. 190r.

13 Sobre el foco palentino, véanse Portela Sandoval, F., La escultura del siglo XVI en Palencia, Palencia, 1977; Parrado del Olmo, J.M., Los escultores seguidores de Berruguete en Palencia, Valladolid, 1981.

14 A.G.D.V. Libro de Fábrica y Visitas de San Boal. 1586-1638. Dato que recogen Marcos Villar, M. A. y Fraile Gómez, A. Ma , Catálogo Monumental de la Provincia de Valladolid. Partido Judicial de Medina del Campo, Valladolid, 2003, p. 170 .

15 Los sitiales que había tallado, se sustituyeron por una sillería neoclásica de mano de Mateo Núñez. El escultor que citan Marcos Villar y Fraile Gómez (op. cit., p. 164) no puede ser otro que el ensamblador al que destinan varias pagos en la documentación.

16 Opino que podría fecharse a principios del siglo XVII sólo por la decoración geométrica que recorre el friso. Aunque de origen manierista, me parece tan decidida y resuelta como la ausencia de decoración vegetal en los aletones del ático, frecuente en este tipo de empresas del último tercio del XVI, no tanto en las del siguiente siglo. Por otro lado, ali- 
Volviendo a Torrelobatón, y a 1632, la tasación firmada por el ensamblador vallisoletano, Pedro de Barrionuevo, del retablo presentado por el entonces entallador para el oratorio de los Medina Carassa no resultó como hubiese querido. El 13 de marzo, "Jossep de la Peña, lo tenia echo y acabado de la talla y escultura y porque no se allaba en dispusiçion para poder darle a pintar y dorar, estaba conbenido y concertado con el dicho Baltassar de Medina de que el susodicho le diese a pintar y dorar en la forma que el quisiere y por bien tubiere, por su quenta y riesgo, con que solo se abia de tasar lo que el abia echo de talla y ensamblaje y no otra cosa"17. Un par de semanas después, el patrono de la capilla, perro viejo, recurre a un maestro de su confianza para peritar la obra. La evaluación de Barrionuevo fue un jarro de agua fría pese a que el retablo no está nada mal, pese a la calidad, en particular, del relieve, y pese a la propia disposición del artista, abierto a cobrar únicamente el trabajo de arquitectura, "regalando" la figura del santo y la escena del ático. En "cuanto a esto, se contenta y satisface con los dichos cinquenta y cinco ducados en que estan conçertados".

La tasación, atenta al conjunto, incluidas imágenes y ornamentación, rebajó a catorce míseros ducados el importe que se había embolsado. Luego de solicitar ejecución sobre su persona y bienes, y ante la negativa a pagar del deudor, el teniente de alguacil "le puso en la carcel desta villa, con unos grillos y una cadena" donde permanecería unos treinta días a la sombra hasta que, tras sentencia inapelable de pagar lo debido, "quitandose las prisiones, se abia ido y ausentado de la dichar carcel".

Los fiadores que actuaron a favor del fugado serían, después, viejos amigos. Fueron Gaspar de Morales, un acaudalado vecino de Nava del Rey; Pedro Cebrián, futuro suegro del artista, de la misma vecindad, y un personaje con el que tenía lazos familiares. Éste, era clérigo, y de cierta importancia: Andrés Gómez de Toro, beneficiado y miembro del cabildo de los Santos Juanes. De él y otros familiares lejanos, tomaría, ya digo, el apellido con el que comienza a señalarse en algunos documentos a partir, más o menos, de $1640^{18}$.

Cuando mueren sus padres y poco después del triste capítulo vivido en Torrelobatón, se traslada a la misma villa de Nava del Rey, donde había más y mejor demanda y donde contaba con una proyección mucho mayor que la deseada en $\mathrm{La} \mathrm{Seca}^{19}$. Allí se casaría, por primera vez, y allí transcurriría una buena parte de su vida hasta su viaje a Salamanca en 1647 para prestar sus servicios, ya no bisoños, a los dominicos de San Esteban ${ }^{20}$.

Del retablo de Torrelobatón, sólo algunos detalles ${ }^{21}$. Primero, que es tan sólo la carta de presentación de un ensamblador-entallador de futuro y con una larga carrera por delante. Que su

menta la autoría el hecho de que las características del retablo en cuestión, coinciden con las condiciones dispuestas en el contrato para el de San Miguel. Veáse en Marcos Villar, M.A. y Fraile Gómez, A.Ma ., op. cit., el doc. 5

17 A.H.P.V. leg. 5006, fol. 130r.

18 He visto en los protocolos relativos a Nava del Rey que, sólo a partir de ese año, firma con el nombre completo y, aun así, no siempre. El dicho Andrés Gómez de Toro otorga testamento -al que sigue el codicilo- en 1633, desvelando los lazos que lo unían con los Cebrián y con el mismo Gaspar de Morales que aparece en el contrato del retablo. A ellos deja parte de la herencia. A.H.P.V., leg. 13463, fols. 171-176v.

19 Pedro de la Peña falleció en diciembre de 1627 y, en octubre de 1631, su viuda, Isabel de Cepejón. Ambos fueron enterrados bajo lápidas paralelas, en la capilla mayor de la iglesia de Santa María de La Seca. A.G.D.V. La Seca. Libro de Difuntos. Tomo I, fols. 279r y 321v.

${ }^{20}$ En 1647 aparece cobrando ciertos recibos, relacionados, creo yo, con la sillería de San Esteban de Salamanca que, por cierto, sí se conserva, y no con la de San Ildefonso de Toro. Ésta sí desapareció. Bonet Correa (op. cit., p. 293) había relacionado a Peña de Toro con el coro salmantino al leer las cuentas que se guardan en el Archivo Histórico Nacional (Clero, libro 10.790, fol. 35v.) Alfonso Rodríguez G. de Ceballos (“Juan Moreno y la arquitectura...", art. cit., p. 271) prefirió, ante los mismos albaranes, adscribirlo al desaparecido del convento toresano. La lectura de los pagos y partidas es verdad que lleva a cierta confusión.

21 Agradezco a José María Gil García, párroco de Torrelobatón, su predisposición para abrir la iglesia y permitirme fotografiar este retablo. 


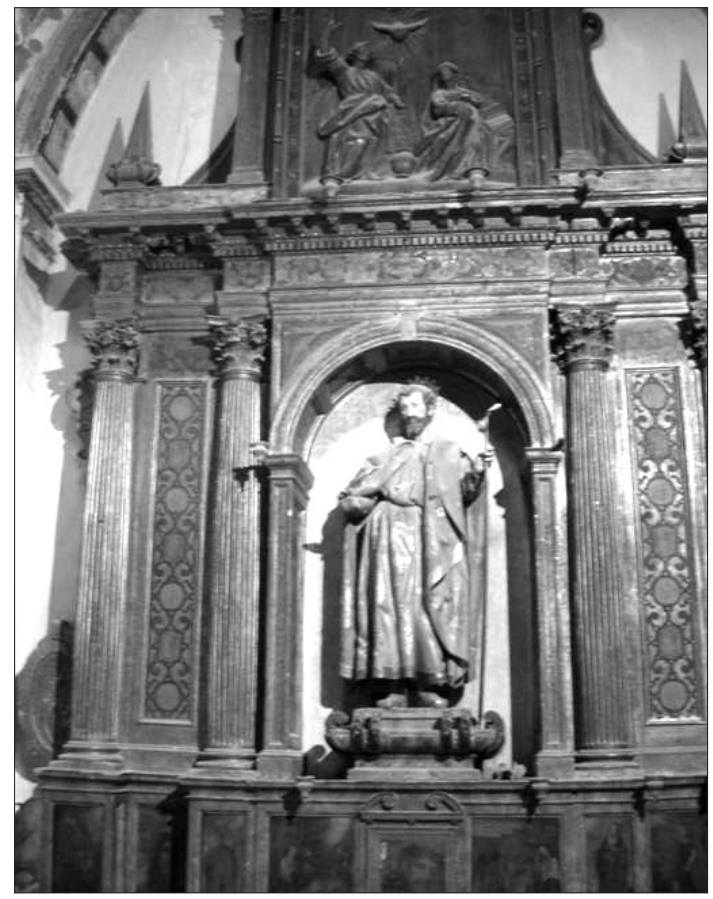

Fig. 1. Retablo de San José. Torrelobatón.

gusto por lo que se viene denominando "clasicismo" es patente y se huele no sólo en esas columnas coronadas por capiteles corintios de manual, sino, más que nada, en la composición sosegada de la estructura, tan bien integrada en el espacio del oratorio -de verdad ínfimo- al que se pliega con absoluto decoro.

La organización es simple (véase la figura 1), con dos pares de fustes estriados de elegante éntasis, dispuestos en tres calles sobre un banco decorado con pinturas y bajo un ático abrochado por pilastras y rematado por un exquisito frontón curvo. Las laterales, accesorias nada más, se visten con paneles de decoración geométrica en la que brilla el protagonismo de la policromía y el oro. La central se abre con un arco de medio punto que acoge al titular. Su intradós, se decora con sutiles casetones mientras que las albanegas se destacan con la punta de diamante propia de la portada clasicista del llamado foco vallisoletano 22 .

El banco, que fluctúa por los salientes de las columnas, se recorre con pinturas en las que campa un pequeño santoral alternado con otras historias de pequeño formato 23 . Más interesante es el ático y cómo se llega a él. El estatismo de principios del XVII, propio de artistas como Muniátegui, parece que empieza a desequilibrarse: los requiebros del banco, advertidos en el contrato, se prolongan en altura provocando que el entablamento se recorte pese a su dependencia formal del modelo clásico 24 . Por tanto, el relieve se conecta mejor con la figura del piso principal al hacer

22 Estudiado por Bustamante García, A., La arquitectura clasicista del foco vallisoletano (1561-1640), Valladolid, 1983.

23 Representan un santo penitente, San Francisco de Asís, una santa, San Agustín, Adoración de los Pastores, un Ecce Homo que ocupa la puerta del Sagrario, una Epifanía, Santa Clara, San Juanito, otra santa y San Miguel. Cfr. Parrado del Olmo, Catálogo Monumental de la Provincia de Valladolid..., op. cit., p. 223

${ }^{24} \mathrm{La}$ mirada a obras inmediatamente anteriores es evidente y se ve que su lección se respeta. Tuvo que conocer el retablo de San Antón que ejecutó Juan de Muniátegui, con la participación de Gregorio Fernández, para la parroquial de los Santos Juanes de la villa de Nava del Rey. 
hincapié en la lectura vertical de la calle, a la que se supedita el resto del mueble. Además, atención a los fragmentos avolutados, un poco tímidos, que se ciñen a ambos lados y, a la receta, tan característica, con que se adereza la portezuela del Sagrario. La moldura acodada que enmarca la escena superior y las pirámides, prácticamente los únicos elementos ornamentales, serán todo un clásico.

Sin tener ya esa absoluta claridad compositiva, sigue siendo una arquitectura-comodín: al espacio propuesto en el cuerpo principal y ático, se acoplaría sin problemas cualquier otro motivo figurativo. De hecho, la historia de Santa Mónica contemplada en la escritura de contrato se sustituyó finalmente por la Anunciación, que me parece que se relaciona mejor con el santo encajado en la hornacina ${ }^{25}$.

El San José, sobre una peana de piedras, gallones y volutas inconfundibles, responde al tipo de Gregorio Fernández, pero, claro, no se acerca a su tratamiento del cabello y la compostura resulta demasiado estática -no tanto si nos olvidamos del citado escultor-, aunque la proporción está bien resuelta y los paños, menos metálicos y hojalatosos que los del gallego, tampoco desmerezcan ${ }^{26}$.

Tanto el relieve del ático, espléndido, como la escultura de bulto, recuerdan el estilo -eso sí, menos gesticulante- con que se manejaba Francisco Alonso de los Ríos en Valladolid, Peñafiel o Tordesillas pero no me convence la relación con el relieve de la iglesia de San Ildefonso de Valladolid, en el que se asume el mismo asunto iconográfico 27.

Ahora bien, ésta es sólo la primera obra conocida y documentada de un artista temprano. Su trabajo por tierras castellanas, en Nava del Rey, Valladolid, Salamanca y quién sabe qué otros lugares, ocuparía, como ya he dicho, más de la mitad de su vida. Tiempo suficiente para concretarse como artista hábil y desplegar en Santiago lo aprendido en ese largo viaje.

\section{Extracto de las}

Condiciones para el retablo que se ha de hazer en la yglesia de Sancta Maria desta villa de Torredelobaton, en la capilla del señor Balthasar de Medina. Son las siguientes:

Primeramente, es condicion que se ha de hazer un pedestal resalteado y en resalto del medio, se ha de hazer una custodia con su tarxeta en la puerta y un caliz con una hostia en ella, y se le han de hazer seis ataxos en los timpanos con sus puertas y caxas para poner reliquias con sus çerraduras las dos puertas y la custodia.

Yten, con condicion que se ha de hazer una caja como lo demuestra la traza con su arco y una cartela en la clave y ha de tener de ondo un pie, vaciada con sus molduras y ataxos.

Yten es condicion que se ha de hazer quatro colunas corintias estriadas de arriba abaxo, con sus vassas y capiteles tallados y han de ser robadas quarta parte y han de tener sus traspilares con sus collarines atados como lo demuestra la traza.

Es condicion que los entrecolunios han de llevar unas platabandas vaciadas y corridas sus medias cañas alrededor de ellas y su collarin atado con los tres pilares, como lo muestra la traza.

Yten es condiçion que se ha de hacer una cornissa corintio con su alquitrabe y frisso, resalteado, como lo demuestra la traza y ha de llevar sus dentellones y cartelas talladas como lo demuestra la traza.

\footnotetext{
25 Lo que denota que no siempre se ceñía el producto final a las condiciones contractuales firmadas ante notario. Seguramente hubo cambios en la preferencia iconográfica acordados de palabra entre el comitente y el artista.

${ }^{26}$ La peana, elemento subsidiario y que debe mirarse con atención, es del tipo de las empleadas para ubicar las esculturas del imaginero de Sarria, pero sin la propensión volumétrica de las de éste. Me recuerda la que pisa la Santa Isabel del retablo central de la capilla mayor del convento dedicado a la santa en la ciudad de Valladolid.

27 La relación formal de ambos relieves de la Anunciación y el escultor Francisco Alonso de los Ríos fue señalada por Urrea Fernández, J., "Escultores coetáneos y discípulos de Gregorio Fernández en Valladolid”, Boletín del Seminario de Estudios de Arte y Arqueología de Valladolid, t. L, 1984, pp. 349-367, nota 67. Del mismo autor, "El escultor Francisco Alonso de los Ríos (?-1960)", B.S.E.A.A.V., t XXXVIII, 1972, pp. 355-369.
} 
Yten es condicion que en el segundo cuerpo ha de llevar un çoclo partido por medio, donde ha de cargar remate y pilastras.

Yten es condicion que se ha de hazer un quadro con sus orexas y sus molduras como lo muestra la traza.

Yten es condicion que se an de hazer unas pilastras con sus capiteles y vassas corintias y por el lado ha de llevar unos arbotantes y sus remates a los lados.

Yten es condicion que se ha de hazer una cornisa corintia con sus dentellones resalteada y encima de la cornisa ha de llevar un frontispicio y a los lados, sus remates...

Yten es condicion que se ha de hazer de madera de pino que no sea teossa.

Yten es condicion que en la caxa principal se ha de hazer un San Joseph de 6 pies de alto para ponerle en el primero encassamiento.

Yten es condicion que en el segundo cuerpo, dentro del quadro, se ha de hazer una Sancta Monica de medio reliebe.

46r-46v. Ante el escribano Diego de Cabrera.

Simón Vicente LóPEZ (Universidad de Santiago de Compostela) 